\title{
Short-Term Associations of Fine Particulate Matter and Synoptic Weather Types with Cardiovascular Mortality: An Ecological Time-Series Study in Shanghai, China
}

\author{
Qing Tian ${ }^{1}$, Mei Li ${ }^{2}$, Scott Montgomery ${ }^{3,4,5}$, Bo Fang ${ }^{6}$, Chunfang Wang ${ }^{6}$, Tian Xia ${ }^{7, *}$ and \\ Yang $\mathrm{Cao}^{3, *(\mathrm{D})}$ \\ 1 Department of Public Health Sciences, Karolinska Institutet, 17177 Stockholm, Sweden; qing.tian@stud.ki.se \\ 2 Center for Assessment of Medical Technology, Örebro University Hospital, Örebro University, \\ 70182 Örebro, Sweden; mei.li@regionorebrolan.se \\ 3 Clinical Epidemiology and Biostatistics, School of Medical Sciences, Örebro University, \\ 70182 Örebro, Sweden; scott.montgomery@oru.se \\ 4 Clinical Epidemiology Division, Department of Medicine, Karolinska Institutet, 17177 Stockholm, Sweden \\ 5 Department of Epidemiology and Public Health, University College London, London WC1E 6BT, UK \\ 6 Division of Vital Statistics, Shanghai Municipal Center for Disease Control and Prevention, \\ Shanghai 200336, China; fangbo@scdc.sh.cn (B.F.); wangchunfang@scdc.sh.cn (C.W.) \\ 7 Institute of Health Information, Shanghai Municipal Center for Disease Control and Prevention, \\ Shanghai 200336, China \\ * Correspondence: xiatian@scdc.sh.cn (T.X.); yang.cao@oru.se (Y.C.); Tel.: +46-19-602-6236 (Y.C.)
}

Received: 24 December 2019; Accepted: 9 February 2020; Published: 10 February 2020

\begin{abstract}
Background: Exposures to both ambient fine particulate matter $\left(\mathrm{PM}_{2.5}\right)$ and extreme weather conditions have been associated with cardiovascular disease (CVD) deaths in numerous epidemiologic studies. However, evidence on the associations with CVD deaths for interaction effects between $\mathrm{PM}_{2.5}$ and weather conditions is still limited. This study aimed to investigate associations of exposures to $\mathrm{PM}_{2.5}$ and weather conditions with cardiovascular mortality, and further to investigate the synergistic or antagonistic effects of ambient air pollutants and synoptic weather types (SWTs). Methods: Information on daily CVD deaths, air pollution, and meteorological conditions between 1 January 2012 and 31 December 2014 was obtained in Shanghai, China. Generalized additive models were used to assess the associations of daily $\mathrm{PM}_{2.5}$ concentrations and meteorological factors with CVD deaths. A 15-day lag analysis was conducted using a polynomial distributed lag model to access the lag patterns for associations with $\mathrm{PM}_{2.5}$. Results: During the study period, the total number of CVD deaths in Shanghai was 59,486, with a daily mean of 54.3 deaths. The average daily $\mathrm{PM}_{2.5}$ concentration was $55.0 \mu \mathrm{g} / \mathrm{m}^{3}$. Each $10 \mu \mathrm{g} / \mathrm{m}^{3}$ increase in $\mathrm{PM}_{2.5}$ concentration was associated with a $1.26 \%$ (95\% confidence interval (CI): $0.40 \%, 2.12 \%$ ) increase in CVD mortality. No SWT was statistically significantly associated with CVD deaths. For the interaction between $\mathrm{PM}_{2.5}$ and SWT, statistically significant interactions were found between $\mathrm{PM}_{2.5}$ and cold weather, with risk for $\mathrm{PM}_{2.5}$ in cold dry SWT decreasing by $1.47 \%$ (95\% CI: $0.54 \%, 2.39 \%)$, and in cold humid SWT the risk decreased by $1.45 \%$ (95\% CI: $0.52 \%, 2.36 \%)$. In the lag effect analysis, statistically significant positive associations were found for $\mathrm{PM}_{2.5}$ in the 1-3 lag days, while no statistically significant effects were found for other lag day periods. Conclusions: Exposure to $\mathrm{PM}_{2.5}$ was associated with short-term increased risk of cardiovascular deaths with some lag effects, while the cold weather may have an antagonistic effect with $\mathrm{PM}_{2.5}$. However, the ecological study design limited the possibility to identify a causal relationship, so prospective studies with individual level data are warranted.
\end{abstract}


Keywords: cardiovascular mortality; air pollution; fine particulate matter; $\mathrm{PM}_{2.5}$; weather; synoptic weather type; interaction effect; antagonistic effect; synergistic effect; lag effect

\section{Introduction}

Exposure to air pollution has been widely acknowledged as an important influencing factor for cardiovascular health [1]. In recent years, evolving epidemiological and clinical research has provided convincing evidence that exposure to air pollution, especially to fine particulate matter or $\mathrm{PM}_{2.5}$, can lead to progression of cardiovascular disease and triggering of acute cardiac events. $\mathrm{PM}_{2.5}$ refers to particulate matters with an aerodynamic equivalent diameter of $2.5 \mu \mathrm{m}$ or less, which can be suspended in the air and inhaled into the lung to reach the alveoli. The higher its concentration in the air, the more serious is the air pollution. Investigations found that inhalation of air pollutants promotes the development of heart failure, arrhythmia, ischemic heart disease, and high blood pressure, and increases the incidence and mortality of cardiovascular diseases (CVD) [2]. Not only cardiovascular and respiratory diseases, but also all-cause mortality could be partly attributable to exposure to $\mathrm{PM}_{2.5}$ air pollution, regardless of the duration of the exposed window period [3,4].

Air pollution is a risk factor that can be modified, and scholars predicted potential mortality benefits of air pollution control in urban China, such that approximately 241,000-1,841,000 life-years could be saved annually for different scenarios of air pollution improvements, indicating substantial health benefits such as a $25 \%$ improvement in hypertension control and $30 \%$ reduction in cigarette control combined [5].

The effects of air pollution on cardiac function are both long term and short term. A recent international study revealed that an increase of $10 \mu \mathrm{g} / \mathrm{m}^{3}$ in the two-day moving average of $\mathrm{PM}_{2.5}$ concentration was associated with increase of $0.55 \%$ ( $95 \%$ confidence interval (CI): $0.45 \%, 0.66 \%$ ) in daily cardiovascular mortality [6]. A systematic review gathered evidence on the long-term effects of exposure to $\mathrm{PM}_{2.5}$, finding that an increase of $10 \mu \mathrm{g} / \mathrm{m}^{3}$ in $\mathrm{PM}_{2.5}$ concentration was associated with as high as $11 \%$ excess CVD mortality [7]. Furthermore, studies discovered that one of the independent modifiable risk factors triggering cardiovascular deaths was a long-term exposure to particulate matter [8,9]. For short-term effects, a meta-analysis in China summarized the evidence and concluded that $0.68 \%$ (95\% CI: $0.39 \%, 0.97 \%$ ) higher incidence of cardiovascular mortality is related to each $10 \mu \mathrm{g} / \mathrm{m}^{3}$ increase in $\mathrm{PM}_{2.5}$ [10]. Evidence from American and European countries also showed similar findings, suggesting that increased $\mathrm{PM}_{2.5}$ levels would significantly increase the risk of CVD deaths $[4,11]$.

Meteorological conditions have been shown to influence daily mortality and disease burden in many studies, especially for the cardiovascular system. Weather conditions such as extreme temperature [12], diurnal temperature range [13,14], temperature variation [15], and humidity [16] have been defined as risk factors or effect modifiers that may contribute to CVD mortality.

However, results from research on ambient temperature and cardiovascular events have been inconsistent. A recent review gathered literature on associations of cold and heat on CVD risk, and concluded that both high and low temperatures were associated with higher cardiovascular risk [17]. In contrast, another review suggested that only heat waves might increase cardiovascular mortality, while cold spells increase the morbidity risk [18]. Excessively hot episodes in tropical areas have been shown to increase CVD mortality by 16.63 times (95\% CI: 10.47, 26.42) compared with other seasons [19]. A study in Hong Kong identified that cold weather was associated with emergency hospital admission for cardiovascular events, with a relative risk (RR) of $1.22(95 \%$ CI: 1.15, 1.29) [20]. Researchers from Vietnam found a $1{ }^{\circ} \mathrm{C}$ decrease in temperature was associated with an increase in CVD admissions of $12 \%$ (95\% CI: 1\%, 25\%) [21]. A case series study in Catalonia concluded that cold spells, but not heat waves, increased the incidence of emergency cardiovascular hospitalizations [22]. 
Other weather factors have also been found associated with cardiovascular health. The presence of extreme weather and sudden decrease in air pressure are associated with more hospital admissions for CVD [23]. Descriptive analysis suggests that both cold, cloudy days and warm, rainy days with high humidity are related to CVD morbidity [24]. Long sunshine duration has been associated with a $15 \%$ increased risk of cardiovascular events [25].

Although $\mathrm{PM}_{2.5}$ and extreme weather conditions have been widely studied, results from research into CVD mortality associated with synergistic or antagonistic effects between $\mathrm{PM}_{2.5}$ and weather conditions remains inconsistent and inconclusive. Many previous studies included meteorological variables as individual covariates, while few of them fully considered the internal relationship of these variables and their collective effects. Importantly, investigations in high-income countries may not be applicable to China, which has one of the largest populations exposed to high levels of air pollution.

Our previous study indicated that $\mathrm{PM}_{2.5}$ together with favorable synoptic weather types (SWTs) was significantly associated with higher non-accidental mortality [26]. Based on our previous findings, we wanted to further investigate the associations between CVD deaths and $\mathrm{PM}_{2.5}$ pollution and weather conditions using a large-scale database of daily mortality in Shanghai, aiming at providing updated evidence on the associations of CVD mortality with $\mathrm{PM}_{2.5}$ and weather conditions, especially the effects of the interaction between air pollutants and the SWT.

\section{Materials and Methods}

\subsection{Study Design and Setting}

The study is observational and ecological, for the time period 1 January 2012 to 31 December 2014 , aiming to access the associations of environmental factors with non-accidental CVD deaths. The environmental factors include air pollutants $\mathrm{PM}_{2.5}$, nitrogen dioxide $\left(\mathrm{NO}_{2}\right)$, sulfur dioxide $\left(\mathrm{SO}_{2}\right)$, six SWTs, and interactions between $\mathrm{PM}_{2.5}$ and SWT.

The population of the study was the residents who were registered in the Household Register of Shanghai (HRS). Shanghai is a municipality and the largest city in the east China, with longitude and latitude of $121^{\circ} \mathrm{E}$ and $31^{\circ} \mathrm{N}$, located in the Yangtze River Delta Region, with a territory of about $6340 \mathrm{~km}^{2}$. Shanghai is the most populous city in the east China with a permanent resident population of around 24.18 million in 2017 and a local gross domestic product of approximately 3.27 trillion Yuan in 2017 [27].

\subsection{Data Collection}

Because $\mathrm{PM}_{2.5}$ was not routinely monitored in Shanghai until the end of 2012, we obtained hourly $\mathrm{PM}_{2.5}$ concentrations in 2012 published by the Shanghai US Consulate General, which was regarded as a reliable source of $\mathrm{PM}_{2.5}$ concentrations in China [28]. Daily average $\mathrm{PM}_{2.5}$ concentrations from 1 January 2013 to 31 December 2014 were obtained from the Shanghai Meteorological Bureau. The data came from only one air monitor during our study period to present the $\mathrm{PM}_{2.5}$ level for the whole city.

Daily weather meteorological data, including temperature, relative humidity, air pressure, wind speed, precipitation, and sunshine hours, during the same period were also obtained from the Shanghai Meteorological Bureau. Weather conditions were categorized into six SWTs using the method introduced by Vanos [29]. The extraction of daily SWT was based on the cluster analysis using measurements of temperature, barometric pressure, humidity, sunshine time, precipitation, and wind velocity, etc. constituting 18 meteorological variables during a day. The final weather types identified in our study included: hot dry, warm humid, cold dry, cool dry, cool humid, and cold humid [26].

Daily CVD mortality data in Shanghai were obtained from the Causes of Death Register of Shanghai (CDRS) provided by the Shanghai Municipal Center for Disease Control and Prevention (SCDC). Mortality from major CVDs was identified according to the International Classification of Diseases, 10th edition (ICD-10) codes I00-I78. There were no district-specific data available in the current study. CVD mortality was represented using daily death counts. Because the total population 
was relatively stable during the study period, we treated it as if it remained unchanged to produce mortality rates.

\subsection{Statistical Analyses}

Descriptive statistical methods were used to describe the characteristics of the variables. Daily CVD mortality and daily concentrations of air pollutants were examined graphically using time-series plots.

Generalized additive models (GAM) were used to assess the associations of exposure to $\mathrm{PM}_{2.5}$ and SWT with CVD mortality [30-32]. The regression models included the following components:

(1) The main risk factors $\mathrm{PM}_{2.5}$ and (2) SWT, using an indicator variable; (3) an interaction term between them; (4) an indicator variable for day of the week (DOW); and (5) a smooth function $S$ for time to control for seasonal trend and unobserved confounders. The final model is described below, which was evaluated using Akaike's information criterion (AIC):

$$
\log \left[E\left(Y_{t}\right)\right]=\beta_{0}+\beta_{1} \cdot P M_{2.5, t}+\beta_{2} \cdot S W T_{t}+\beta_{3} \cdot P M_{2.5, t} \times S W T_{t}+\beta_{4} \cdot D O W_{t}+S(t)
$$

where $E\left(Y_{t}\right)$ refers to the expected cardiovascular deaths on day $t ; \beta_{0}$ represents the intercept; $\beta_{1}-\beta_{4}$ refer to the coefficients for each variable; $P M_{2.5, t}$ represents the daily average $\mathrm{PM}_{2.5}$ concentration on day $t$; $D O W t$ represents a $6 \times 1$ vector of DOW for day $t$; $S W T_{t}$ denotes a $5 \times 1$ vector of SWT for day $t$; $\mathrm{PM}_{2.5, t} \times S W T_{t}$ denotes the interaction between $\mathrm{PM}_{2.5}$ and SWT for day $t . S(t)$ is a smoothing function implemented by cubic B-splines, giving associations with unobserved factors and seasonal trends [33]. According to the AIC, we used a total of 45 knots for the splines to present the time trend and capture the true underlying parameters.

We also examined the 15-day lag patterns of $\mathrm{PM}_{2.5}$ by applying the polynomial distributed lag model (DLM) with the same splines to control for the nonlinear time trend [34]. The reason that 15 days were chosen as a lag period was to assess the short-term effects of $\mathrm{PM}_{2.5}$.

All statistical analyses were performed using the packages mgcv and dlnm in the software R 3.6.1 (R Foundation for Statistical Computing, Vienna, Austria). Statistical graphing was achieved using the packages plotrix and ggplot2 in R. Two-sided statistical tests were performed, and the regression coefficients with a $P$-value $<0.05$ were considered statistically significant. To check the robustness of our model, a sensitivity analysis was applied by changing the knots in the smoothness of time and adding the co-exposed pollutants $\mathrm{NO}_{2}$ and $\mathrm{SO}_{2}$ in the models.

\subsection{Ethical Consideration and Data Availability}

The study is an ecological and observational study, based on the data from population-based registers in Shanghai. No personal identification was disclosed in our data. The study was approved by the Ethical Review Committee of the SCDC (approval number: SCDC2016-08).

The use of the data was under the agreement between the Institute of Environmental Medicine, Karolinska Institutet, Sweden and the SCDC within a bilateral collaboration framework. The data were not publicly available but may be available upon reasonable request and with permission of the SCDC (xiatian@scdc.sh.cn).

\section{Results}

\subsection{Characteristics of CVD Mortality, $P M_{2.5}$ Concentration, and Meteorological Conditions}

During the study period, a total of 59,486 CVD deaths occurred in Shanghai, with a mean of 54.3 daily deaths and a median of 51. Distribution of daily CVD deaths approximated to a quasi-Poisson distribution with a mean of 54.3 and an overdispersion index of 1.47. Overall, the annual average concentrations of $\mathrm{PM}_{2.5}$ in Shanghai was $55.0 \mu \mathrm{g} / \mathrm{m}^{3}$, with a median value of $45.5 \mu \mathrm{g} / \mathrm{m}^{3}$. In general, the daily average $\mathrm{PM}_{2.5}$ concentrations and the numbers of daily deaths show similar seasonal trends. For both measurements, the values presented high in cold seasons and low in the warm seasons (Figure 1). 
The predicted daily death counts by the GAM, including $\mathrm{PM}_{2.5}$, DOW, SWT, and the interactions between $\mathrm{PM}_{2.5}$ and SWT, indicate that $71.2 \%$ of the deviance can be explained by the model.

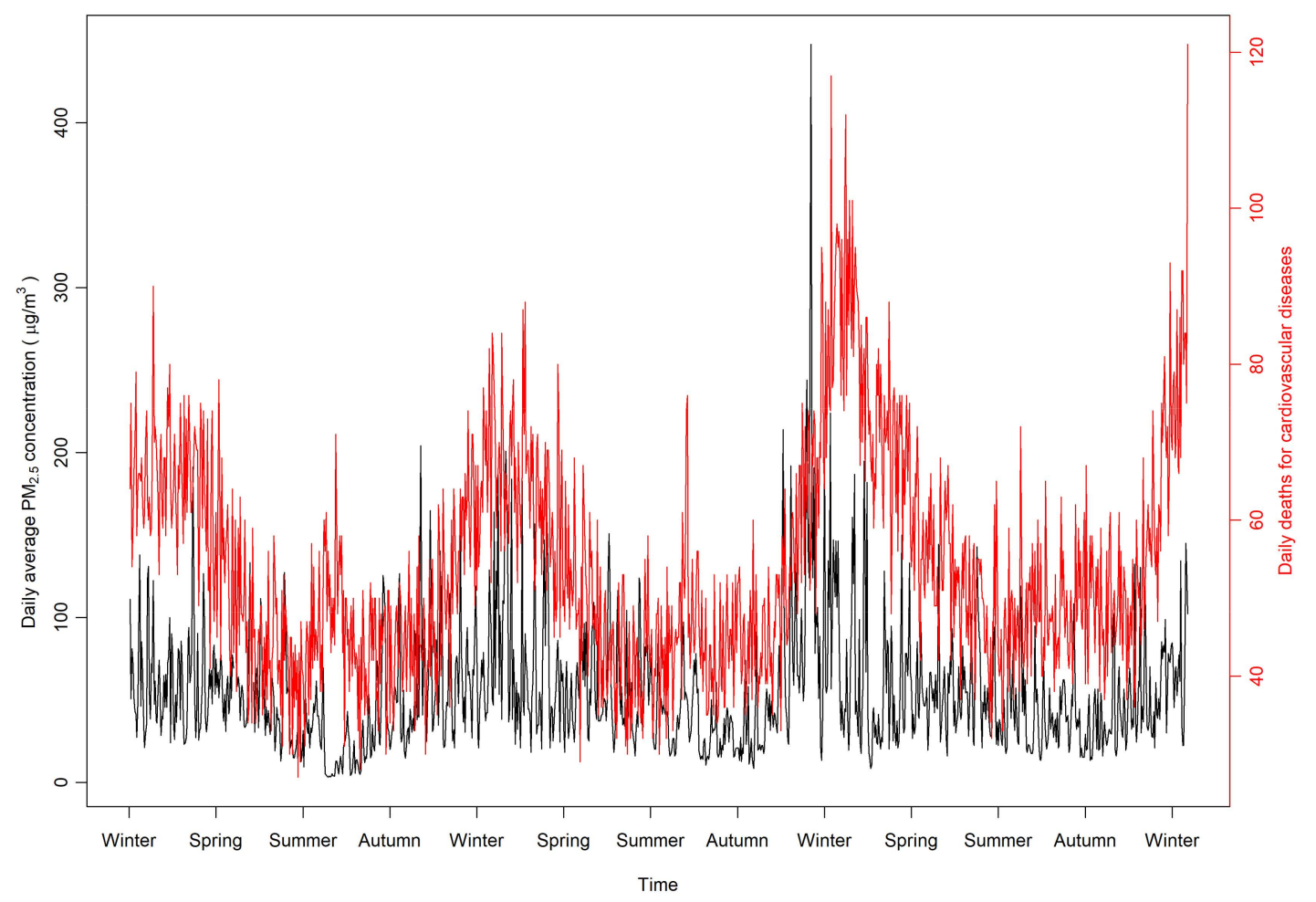

Figure 1. Time trends of daily ambient fine particulate matter $\left(\mathrm{PM}_{2.5}\right)$ concentrations and cardiovascular disease (CVD) deaths.

The meteorological features of the six SWTs were described in detail in our previous study and are also provided in the Supplementary Table S1 [26]. In general, the annual average temperature in Shanghai is $17.2^{\circ} \mathrm{C}$, and the precipitation is about $1190 \mathrm{~mm}$ a year. The humid SWT, including warm humid, cold humid, and moderate humid days, occurs nearly half $(49.8 \%)$ of the days, while dry weather occurs for the other half. Average levels of $\mathrm{PM}_{2.5}, \mathrm{SO}_{2}$, and $\mathrm{NO}_{2}$ by SWT are provided in the Supplementary Table S2.

\subsection{Effects of $P M_{2.5}$, SWT, and Their Interactions on CVD Mortality}

The effects of $\mathrm{PM}_{2.5}$ and SWT on CVD deaths are shown in Table 1. Both the models with (adjusted $\mathrm{R}^{2}=0.704$ ) and without (adjusted $\mathrm{R}^{2}=0.705$ ) the co-exposed pollutants $\mathrm{SO}_{2}$ and $\mathrm{NO}_{2}$ show similar statistically significant associations between $\mathrm{PM}_{2.5}$ and CVD deaths. However, no statistically significant association was found between $\mathrm{SO}_{2}$ (risk ratio $(\mathrm{RR})=1.0007,95 \% \mathrm{CI}$ : $0.9993,1.0021$ ) or $\mathrm{NO}_{2}$ $\left(\mathrm{RR}=0.9998,95 \%\right.$ CI: 0.9990, 1.0005) and CVD deaths in our data (Table 1). Without adjusting for $\mathrm{SO}_{2}$ and $\mathrm{NO}_{2}$, each $10 \mu \mathrm{g} / \mathrm{m}^{3}$ increase in $\mathrm{PM}_{2.5}$ concentration was associated with $1.26 \%$ (95\% CI: $0.40 \%$, $2.12 \%)$ increase in daily CVD mortality ( $R R=1.0126,95 \mathrm{CI}: 1.0040,1.0212$; Table 1$)$. 
Table 1. Associations of $\mathrm{PM}_{2.5}$, synoptic weather types (SWTs), and their interactions with daily cardiovascular mortality.

\begin{tabular}{|c|c|c|c|c|}
\hline \multirow{3}{*}{ Variable } & \multicolumn{4}{|c|}{ Risk Ratio (RR) for Cardiovascular Mortality } \\
\hline & \multicolumn{2}{|c|}{ Model without $\mathrm{SO}_{2}, \mathrm{NO}_{2}$} & \multicolumn{2}{|c|}{ Model with $\mathrm{SO}_{2}, \mathrm{NO}_{2}$} \\
\hline & RR $(95 \% \mathrm{CI})$ & $P$-Value & RR $(95 \%$ CI) & $P$-Value \\
\hline $\mathrm{PM}_{2.5}\left(\right.$ per $\left.10 \mu \mathrm{g} / \mathrm{m}^{3}\right)$ & $1.0126(1.0040,1.0212)$ & 0.004 & $1.0121(1.0027,1.0215)$ & 0.011 \\
\hline $\mathrm{SO}_{2}$ & & & $1.0007(0.9993,1.0021)$ & 0.310 \\
\hline $\mathrm{NO}_{2}$ & & & $0.9998(0.9990,1.0005)$ & 0.544 \\
\hline \multirow{2}{*}{\multicolumn{5}{|c|}{$\begin{array}{l}\text { Synoptic weather types } \\
\text { Hot dry (Ref) }\end{array}$}} \\
\hline & & & & \\
\hline Warm humid & $0.9945(0.9359,1.0567)$ & 0.858 & $0.9971(0.9378,1.0603)$ & 0.927 \\
\hline Cold dry & $0.9894(0.9191,1.0651)$ & 0.778 & $0.9861(0.9149,1.0628)$ & 0.714 \\
\hline Cool dry & $0.9954(0.9308,1.0645)$ & 0.893 & $0.9978(0.9327,1.0674)$ & 0.948 \\
\hline Cool humid & $1.0369(0.9666,1.1123)$ & 0.311 & $1.0378(0.9675,1.1133)$ & 0.300 \\
\hline Cold humid & $1.0138(0.9438,1.0891)$ & 0.707 & $1.0157(0.9451,1.0914)$ & 0.672 \\
\hline \multicolumn{5}{|l|}{ Day of week } \\
\hline \multicolumn{5}{|l|}{ Sunday (Ref) } \\
\hline Monday & $1.0269(0.9963,1.0585)$ & 0.085 & $1.0269(0.9963,1.0585)$ & 0.086 \\
\hline Tuesday & $1.0178(0.9874,1.0491)$ & 0.254 & $1.0182(0.9876,1.0497)$ & 0.246 \\
\hline Wednesday & $1.0350(1.0043,1.0667)$ & 0.025 & $1.0352(1.0041,1.0672)$ & 0.026 \\
\hline Thursday & $1.0139(0.9835,1.0453)$ & 0.373 & $1.0143(0.9837,1.0458)$ & 0.363 \\
\hline Friday & $1.0058(0.9756,1.0369)$ & 0.712 & $1.0065(0.9761,1.0378)$ & 0.681 \\
\hline Saturday & $1.0315(1.0008,1.0632)$ & 0.044 & $1.0320(1.0012,1.0637)$ & 0.042 \\
\hline \multicolumn{5}{|l|}{ Interaction } \\
\hline \multicolumn{5}{|l|}{$\mathrm{PM}_{2.5} \times$ Hot dry (Ref) } \\
\hline $\mathrm{PM}_{2.5} \times$ Warm humid & $0.9924(0.9822,1.0027)$ & 0.149 & $0.9926(0.9822,1.0030)$ & 0.162 \\
\hline $\mathrm{PM}_{2.5} \times$ Cold dry & $0.9853(0.9761,0.9946)$ & 0.002 & $0.9852(0.9758,0.9946)$ & 0.002 \\
\hline $\mathrm{PM}_{2.5} \times$ Cool dry & $0.9905(0.9802,1.0009)$ & 0.074 & $0.9904(0.9800,1.0009)$ & 0.072 \\
\hline $\mathrm{PM}_{2.5} \times$ Cool humid & $0.9889(0.9762,1.0019)$ & 0.093 & $0.9893(0.9764,1.0022)$ & 0.104 \\
\hline $\mathbf{P M}_{2.5} \times$ Cold humid & $0.9855(0.9764,0.9948)$ & 0.002 & $0.9853(0.9760,0.9946)$ & 0.002 \\
\hline
\end{tabular}

Ref, reference group; CI, confidence interval, Bold items, variables with statistical significance $(P$-value $<0.05)$.

None of the SWTs alone had a statistically significant association with CVD deaths. Nevertheless, humid weather tended to have a higher-magnitude association with CVD deaths. Compared to hot dry SWT, cool humid SWT had positive association with mortality ( $R R=1.037,95 \%$ CI: 0.967, 1.112), followed by cold humid SWT (RR $=1.014,95 \%$ CI: 0.944, 1.089). In contrast, cold dry SWT had a negative association ( $R R=0.989,95 \%$ CI: $0.919,1.065$ ).

In terms of interaction between the air pollutant and SWT, the interaction between $\mathrm{PM}_{2.5}$ and cold SWT had the largest association compared with other interactions. Statistically significant interactions were found between $\mathrm{PM}_{2.5}$ and cold dry SWT (RR $\left.=0.985,95 \% \mathrm{CI}: 0.976,0.995\right)$ and cold humid SWT $(\mathrm{RR}=0.986,95 \%$ CI: 0.976, 0.995) (Table 1).

\subsection{Lag Effect of $P M_{2.5}$ on CVD Mortality}

The lag effects of exposure to $\mathrm{PM}_{2.5}$ on CVD mortality based on the polynomial DLM analysis are shown in Figure 2a,b and Table 2. Figure 2a illustrates the single-day lag effects of $\mathrm{PM}_{2.5}$ on with CVD mortality associated with a $10 \mu \mathrm{g} / \mathrm{m}^{3}$ increase in $\mathrm{PM}_{2.5}$. Figure $2 \mathrm{~b}$ illustrates the cumulative lag effects on CVD mortality associated with a $10 \mu \mathrm{g} / \mathrm{m}^{3}$ increase in $\mathrm{PM}_{2.5}$ concentration. 


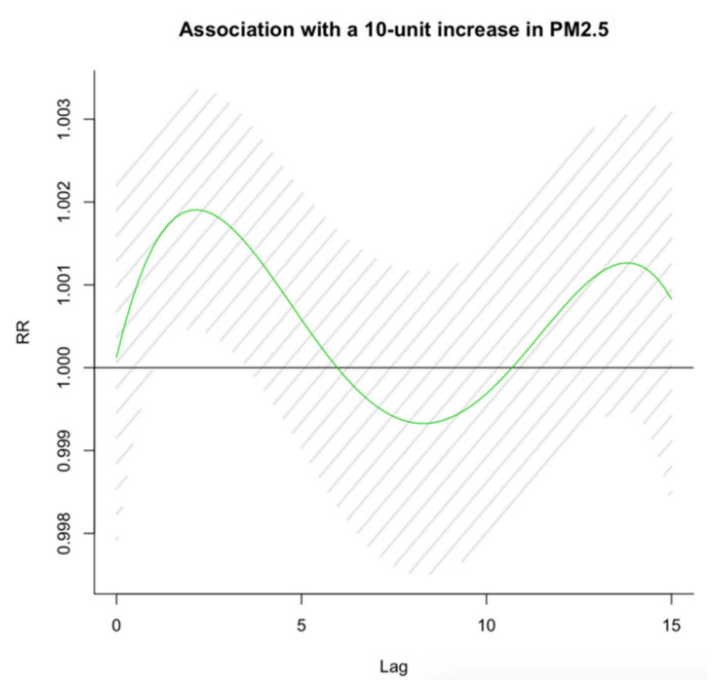

(a)

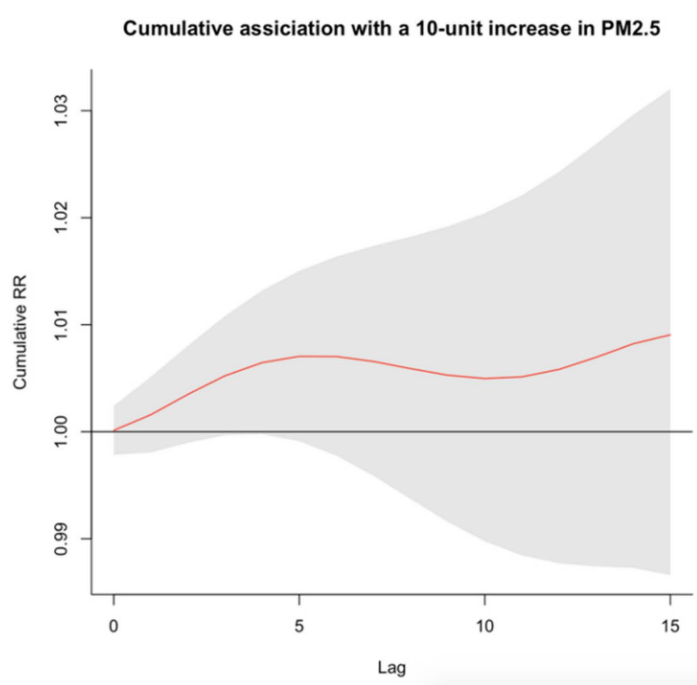

(b)

Figure 2. (a) Fifteen-day lag patterns and (b) cumulative lag patterns of risk for $\mathrm{PM}_{2.5}$-associated CVD mortality. The $x$-axes are lag days, ranging from lag day 0 to lag day 15 ; the $y$-axes are risk ratio (RR) or cumulative RR with 95\% confidence interval for daily CVD mortality per $10 \mu \mathrm{g} / \mathrm{m}^{3}$ increase in $\mathrm{PM}_{2.5}$ concentration.

Table 2. Risk ratio (95\% confidence interval) of lag effects for single days and cumulative lag effects per $10 \mu \mathrm{g} / \mathrm{m}^{3}$ increase in $\mathrm{PM}_{2.5}$ concentration.

\begin{tabular}{ccc}
\hline Lag Day & Single Day Effect & Cumulative Effect \\
\hline Lag 0 & $1.0001(0.9978,1.0024)$ & $1.0001(0.9978,1.0024)$ \\
Lag 1 & $\mathbf{1 . 0 0 0 5}(\mathbf{1 . 0 0 0 0 , \mathbf { 1 . 0 0 2 9 } )}$ & $1.0016(0.9980,1.0051)$ \\
Lag 2 & $\mathbf{1 . 0 0 1 9}(\mathbf{1 . 0 0 0 4}, \mathbf{1 . 0 0 3 3})$ & $1.0035(0.9990,1.0080)$ \\
Lag 3 & $\mathbf{1 . 0 0 1 7}(\mathbf{1 . 0 0 0 3}, \mathbf{1 . 0 0 3 2})$ & $1.0052(0.9997,1.0108)$ \\
Lag 4 & $1.0012(0.9997,1.0027)$ & $1.0065(0.9998,1.0132)$ \\
Lag 5 & $1.0006(0.9990,1.0021)$ & $1.0070(0.9991,1.0150)$ \\
Lag 6 & $1.0000(0.9983,1.0016)$ & $1.0070(0.9978,1.0164)$ \\
Lag 7 & $0.9995(0.9978,1.0013)$ & $1.0066(0.9959,1.0174)$ \\
Lag 8 & $0.9993(0.9975,1.0012)$ & $1.0059(0.9937,1.0182)$ \\
Lag 9 & $0.9994(0.9978,1.0012)$ & $1.0053(0.9916,1.0192)$ \\
Lag 10 & $0.9997(0.9979,1.0015)$ & $1.0050(0.9898,1.0204)$ \\
Lag 11 & $1.0002(0.9983,1.0020)$ & $1.0051(0.9884,1.0221)$ \\
Lag 12 & $1.0007(0.9989,1.0025)$ & $1.0058(0.9877,1.0243)$ \\
Lag 13 & $1.0011(0.9993,1.0029)$ & $1.0070(0.9874,1.0268)$ \\
Lag 14 & $1.0013(0.9995,1.0031)$ & $1.0082(0.9873,1.0296)$ \\
Lag 15 & $1.0008(0.9983,1.0033)$ & $1.0091(0.9866,1.0320)$ \\
\hline
\end{tabular}

Bold items, variables with statistical significance $(P$-value $<0.05)$.

Generally, the associations of $\mathrm{PM}_{2.5}$ with CVD deaths presented a tri-phase pattern within the 15 days, as seen in Figure 2a. Statistically significant effects of $\mathrm{PM}_{2.5}$ in single lag day on CVD mortality were observed between lag day 1 and day 3 , and the largest magnitude association on the second and the third lag days ( $R R=1.0019,95 \%$ CI: $1.0004-1.0033 ; \mathrm{RR}=1.0017,95 \%$ CI: $1.0003-1.0032$, respectively). A harvesting effect [35], i.e., the decrease in overall CVD mortality during the subsequent days, was found between lag days 6 and 11 (Figure 2a,b). However, the effect was not statistically significant.

For cumulative lag effects, although no statistically significant effects was found for all lag days, the largest effects were found for lag days 14 and 15 ( $R R=1.0082,95 \% \mathrm{CI}: 0.9873,1.0296$; $R R=1.0091$, 95\% CI: $0.9866,1.0320$, respectively) followed by lags 5 and 6 (RR $=1.0070,95 \%$ CI: 0.9991, 1.0150; $\mathrm{RR}=1.0070,95 \%$ CI: 0.9978, 1.0164, respectively) (Table 2). 


\subsection{Sensitivity Analysis}

Multi-pollutants including $\mathrm{PM}_{2.5}, \mathrm{SO}_{2}$, and $\mathrm{NO}_{2}$ were included in both the GAM analyses (Table 1) and polynomial DLM analyses (data not shown) to compare with the single-pollutant model. The results remained almost unchanged.

\section{Discussion}

Our study focuses on the short-term associations of ambient air pollutant $\mathrm{PM}_{2.5}$, SWT, and their interaction with daily CVD mortality between 2012 and 2014 in Shanghai, China. The average daily concentration of $\mathrm{PM}_{2.5}$ in Shanghai was $55.0 \mu \mathrm{g} / \mathrm{m}^{3}$, which is much higher than the reference value in the World Health Organization guidelines $\left(10 \mu \mathrm{g} / \mathrm{m}^{3}\right.$ for the annual mean) [36]. In this study, we found that a $10 \mu \mathrm{g} / \mathrm{m}^{3}$ increase in $\mathrm{PM}_{2.5}$ was associated with an overall $1.26 \%$ (95\% CI: $0.40 \%, 2.12 \%$ ) increase in acute CVD mortality, which is of higher magnitude than the results from other studies (between $0.63 \%$ and $0.80 \%$ ) $[6,10,37,38]$. A multicenter meta-analysis in East Asia including Shanghai suggested that each $10 \mu \mathrm{g} / \mathrm{m}^{3}$ increase in $\mathrm{PM}_{2.5}$ was related to a $0.96 \%$ (95\% CI: $0.46 \%, 1.46 \%$ ) increase in cardiovascular mortality [39], which is similar to our study. The lag analysis in our study also indicates that the associations of $\mathrm{PM}_{2.5}$ with CVDs mortality are mainly within the first six days (from lag 0 to lag 5).

We also tried to assess whether there is an association between the SWT and CVD deaths. However, no statistically significant association was found for any SWT in our data. The results are similar to those for Shenzhen, another populous city in China, i.e., no detectable association was found in extreme weather and cardiovascular events [40]. It is of note that we found interactions between cold SWT and $\mathrm{PM}_{2.5}$ which were inversely associated with the risk of CVD deaths, i.e., cold weather was found to potentially compensate the adverse effect of $\mathrm{PM}_{2.5}$ on cardiovascular health. Some other research is consistent with our results. Vanos et al. conducted an investigation in ten cities in Canada on the combined effect of weather and air pollution, and found that cool days were less harmful for cardiovascular-related mortality [41]. In European countries, the relationship between air pollutants and cardiovascular mortality has been found to be overall positive and of higher magnitude at high air temperatures [42]. In Asia, a study in Korea also found similar modification effects [43].

Although the relationship between cardiovascular mortality and weather condition has been widely investigated, few studies have categorized weather types and analyzed the interaction with air pollution. SWT comprises more than just humidity, temperature, and diurnal temperature; instead, it includes the already known and potentially unknown meteorological characteristics relevant to mortality. If we only include individual meteorological variables as covariates in the regression models, bias could be produced in the model because of the exclusion of other variables. The statistically non-significant associations between the SWT alone and CVD deaths in our study may be due to the insufficient data or short time period, and the categorization of SWT also deserves further investigation

According to our lag analysis, the lag association of $\mathrm{PM}_{2.5}$ with CVD mortality kept statistically significant for about 4 days, from lag day 0 to day 3 , while cumulative lag effects were not statistically significantly related to increased CVD mortality. The results suggest that the effects of $\mathrm{PM}_{2.5}$ is acute in terms of CVD deaths. Other studies discovered similar findings. Results from a national study in the U.S. showed on lag day 0 and 1, $\mathrm{PM}_{2.5}$ had the largest effect on CVDs [44]. Another study in Beijing also discovered $\mathrm{PM}_{2.5}$ 's lag effects within 0-3 lag days [45]. Higher levels of gaseous components, including $\mathrm{NO}_{2}$ and $\mathrm{SO}_{2}$, have long been associated with poorer cardiovascular health [46,47]. A systematic review of the studies in China indicated that a $10 \mu \mathrm{g} / \mathrm{m}^{3}$ increase in the concentrations of $\mathrm{NO}_{2}$ and $\mathrm{SO}_{2}$ was associated with a $1.12 \%(95 \% \mathrm{CI}: 0.76 \%, 1.48 \%)$ and $0.75 \%(95 \% \mathrm{CI}: 0.42 \%, 1.09 \%)$ increase in cardiovascular mortality, respectively [10]. No statistically significant associations of $\mathrm{NO}_{2}$ and $\mathrm{SO}_{2}$ observed in our study may be due to the different modeling strategy (no SWT and interaction were used in previous studies) or the relative shorter time period in our study, which should be investigated using long-term time-series data [48]. 
Based on our findings, air pollution, in the top five risk factors for health, has increased CVD mortality with modification from SWT, and might cause heavy burden on health and social development in view of the large population in Shanghai, China. Though the association is subtle, air pollution and extreme weather together have a great excessive impact when considering the entire population. Learning from the Chinese experience $[49,50]$, governments are supposed to continue strengthening control on air pollution, in order to reduce mortality and related costs. For individuals, it is suggested that the population should reduce travel in hot weather, especially with high levels of air pollution, and they can employ physical or dietary interventions, which offer protection against short-term air pollution-induced adverse cardiovascular responses [51,52].

There are some strengths and limitations to our study. To some extent, the study provides new evidence about environmental conditions associated with health, for few other studies investigated the interaction between air pollutants and weather conditions. Therefore, this study might contribute to the pool of global knowledge regarding this topic. Second, SWTs rather than individual meteorological variables should be used to control for weather conditions, which examine the biological effect as the organism's response to weather conditions as a whole, rather than to individual meteorological variables [53]. However, there are also limitation in our study. First, because of different socioeconomic condition and climates, the lessons and experiences learned from our study are hard to generalize to other cities and populations. Secondly, because of the ecological nature of this study, the study design restricted us in exploring the causal nature of relationships. However, since weather can influence the whole region, it is hard to measure those variables at individual level sufficiently in a large population. Thirdly, the lag analysis was only conducted for $\mathrm{PM}_{2.5}$, because the method only takes continuous variables while SWT is a categorical variable. Fourth, no interaction between lags time for $\mathrm{PM}_{2.5}$ and SWT was examined in the lag analysis, because when too many interaction terms (in total 75 interaction terms for 15 lag days and 6 SWTs even when no cross-basis matrix for the interactions was taken into account) were included, the model failed to estimate the parameters. Considering the acute antagonistic effect found between $\mathrm{PM}_{2.5}$ and cold SWT, and the largest cumulative effect found for lag day 15 , the $\mathrm{PM}_{2.5}$ 's lag effects and their interaction with SWT deserve further investigation using appropriate models.

We recognize that the pollution data from a single monitoring station could not accurately reflect the distribution of the $\mathrm{PM}_{2.5}$ concentrations in Shanghai. However, we interpreted the associations between CVD deaths and the risk factors using the relative risk (RR), i.e., mortality rate ratio. Theoretically, the coefficient of $\mathrm{PM}_{2.5}$ in the regression model (or its exponential format RR) only depends on the change in $\mathrm{PM}_{2.5}$ levels but not on the absolute $\mathrm{PM}_{2.5}$ levels, and the coefficient $\beta_{0}$ (or baseline mortality rate) was not of the interest in our study. Therefore, the estimation of $\mathrm{PM}_{2.5}$ 's effect is valid when the change in $\mathrm{PM}_{2.5}$ from the single station might reflect the change in $\mathrm{PM}_{2.5}$ of the whole of Shanghai city, i.e., when the single station's PM $_{2.5}$ level increased, Shanghai city's PM $_{2.5}$ level also increased and vice versa. We would also like to point out that Shanghai is the city with the highest life expectancy in China and one of the highest in the world, therefore, we must explain the results cautiously and cannot generalize them to other parts of China.

\section{Conclusions}

Exposure to $\mathrm{PM}_{2.5}$ was associated with increased short-term risk of CVD deaths with lag effects within four days in Shanghai, China, while cold weather was associated with lower risk. Since the ecological study design restricted us in identifying causal relationships, in-depth prospective studies with individual level data are warranted in the future.

Supplementary Materials: The following are available online at http://www.mdpi.com/1660-4601/17/3/1111/s1, Table S1: Meteorological characteristics of the six synoptic weather types (SWTs) in Shanghai, 2012-2014, Table S2: Daily average levels of the three pollutants by SWT in Shanghai, 2012-2014.

Author Contributions: Data curation, B.F. and T.X.; formal analysis, Q.T. and Y.C.; investigation, B.F., C.W., and T.X.; methodology, M.L., S.M., and Y.C.; project administration, Y.C.; resources, C.W. and Y.C.; software, 
Y.C.; supervision, S.M. and Y.C.; visualization, Q.T.; writing-original draft, Q.T. and M.L.; writing-review and editing, Q.T., M.L., S.M., B.F., C.W., T.X., and Y.C. All authors have read and agreed to the published version of the manuscript.

Funding: This work was supported by a grant from the National Natural Science Foundation of China, approval no.: 31971485 (C.W., T.X., and B.F.).

Acknowledgments: We thank the Shanghai Municipal Center for Disease Control and Prevention for their cooperation in data retrieval and cleaning.

Conflicts of Interest: The funding body was not involved in the design of the study, data collection and analysis, interpretation of results, or writing the manuscript. The authors declare no conflict of interest.

\section{References}

1. Brunekreef, B.; Beelen, R.; Hoek, G.; Schouten, L.; Bausch-Goldbohm, S.; Fischer, P.; Armstrong, B.; Hughes, E.; Jerrett, M.; van den Brandt, P. Effects of long-term exposure to traffic-related air pollution on respiratory and cardiovascular mortality in the Netherlands: The NLCS-AIR study. Res. Rep. Health Eff. Inst. 2009, 139, 5-71.

2. Meo, S.A.; Suraya, F. Effect of environmental air pollution on cardiovascular diseases. Eur. Rev. Med. Pharmacol. Sci. 2015, 19, 4890-4897. [PubMed]

3. Shang, Y.; Sun, Z.; Cao, J.; Wang, X.; Zhong, L.; Bi, X.; Li, H.; Liu, W.; Zhu, T.; Huang, W. Systematic review of Chinese studies of short-term exposure to air pollution and daily mortality. Environ. Int. 2013, 54, $100-111$. [CrossRef] [PubMed]

4. Pinault, L.L.; Weichenthal, S.; Grouse, D.L.; Brauer, M.; Erickson, A.; van Donkelaar, A.; Martin, R.V.; Hystad, P.; Chen, H.; Fines, P.; et al. Associations between fine particulate matter and mortality in the 2001 Canadian Census Health and Environment Cohort. Environ. Res. 2017, 159, 406-415. [CrossRef]

5. Huang, C.; Moran, A.E.; Coxson, P.G.; Yang, X.; Liu, F.; Cao, J.; Chen, K.; Wang, M.; He, J.; Goldman, L.; et al. Potential Cardiovascular and Total Mortality Benefits of Air Pollution Control in Urban China. Circulation 2017, 136, 1575-1584. [CrossRef]

6. Liu, C.; Chen, R.; Sera, F.; Vicedo-Cabrera, A.M.; Guo, Y.; Tong, S.; Coelho, M.; Saldiva, P.H.N.; Lavigne, E.; Matus, P.; et al. Ambient Particulate Air Pollution and Daily Mortality in 652 Cities. N. Engl. J. Med. 2019, 381, 705-715. [CrossRef]

7. Bourdrel, T.; Bind, M.A.; Bejot, Y.; Morel, O.; Argacha, J.F. Cardiovascular effects of air pollution. Arch. Cardiovasc. Dis. 2017, 110, 634-642. [CrossRef]

8. Argacha, J.F.; Bourdrel, T.; van de Borne, P. Ecology of the cardiovascular system: A focus on air-related environmental factors. Trends Cardiovasc. Med. 2018, 28, 112-126. [CrossRef]

9. Kim, H.; Kim, J.; Kim, S.; Kang, S.H.; Kim, H.J.; Kim, H.; Heo, J.; Yi, S.M.; Kim, K.; Youn, T.J.; et al. Cardiovascular Effects of Long-Term Exposure to Air Pollution: A Population-Based Study with 900,845 Person-Years of Follow-up. J. Am. Heart Assoc. 2017, 6. [CrossRef]

10. Zhao, L.; Liang, H.R.; Chen, F.Y.; Chen, Z.; Guan, W.J.; Li, J.H. Association between air pollution and cardiovascular mortality in China: A systematic review and meta-analysis. Oncotarget 2017, 8, 66438-66448. [CrossRef]

11. Vidale, S.; Arnaboldi, M.; Bosio, V.; Corrado, G.; Guidotti, M.; Sterzi, R.; Campana, C. Short-term air pollution exposure and cardiovascular events: A 10-year study in the urban area of Como, Italy. Int. J. Cardiol. 2017, 248, 389-393. [CrossRef] [PubMed]

12. Zhang, Y.; Yu, C.; Bao, J.; Li, X. Impact of temperature on mortality in Hubei, China: A multi-county time series analysis. Sci. Rep. 2017, 7, 45093. [CrossRef] [PubMed]

13. Zhang, Y.; Yu, C.; Yang, J.; Zhang, L.; Cui, F. Diurnal Temperature Range in Relation to Daily Mortality and Years of Life Lost in Wuhan, China. Int. J. Environ. Res. Public Health 2017, 14, 891. [CrossRef]

14. Zhang, Y.; Peng, M.; Wang, L.; Yu, C. Association of diurnal temperature range with daily mortality in England and Wales: A nationwide time-series study. Sci. Total Environ. 2018, 619, 291-300. [CrossRef]

15. Zhang, Y.; Yu, C.; Bao, J.; Li, X. Impact of temperature variation on mortality: An observational study from 12 counties across Hubei Province in China. Sci. Total Environ. 2017, 587, 196-203. [CrossRef] [PubMed]

16. Zeng, J.; Zhang, X.H.; Yang, J.; Bao, J.Z.; Xiang, H.; Dear, K.; Liu, Q.Y.; Lin, S.; Lawrence, W.R.; Lin, A.H.; et al. Humidity May Modify the Relationship between Temperature and Cardiovascular Mortality in Zhejiang Province, China. Int. J. Environ. Res. Public Health 2017, 14, 1383. [CrossRef] 
17. Liu, C.; Yavar, Z.; Sun, Q. Cardiovascular response to thermoregulatory challenges. Am. J. Physiol. Heart Circ. Physiol. 2015, 309, H1793-H1812. [CrossRef]

18. Song, X.; Wang, S.; Hu, Y.; Yue, M.; Zhang, T.; Liu, Y.; Tian, J.; Shang, K. Impact of ambient temperature on morbidity and mortality: An overview of reviews. Sci. Total Environ. 2017, 586, 241-254. [CrossRef]

19. Mendez-Lazaro, P.A.; Perez-Cardona, C.M.; Rodriguez, E.; Martinez, O.; Taboas, M.; Bocanegra, A.; Mendez-Tejeda, R. Climate change, heat, and mortality in the tropical urban area of San Juan, Puerto Rico. Int. J. Biometeorol. 2018, 62, 699-707. [CrossRef]

20. Tian, L.; Qiu, H.; Sun, S.; Lin, H. Emergency Cardiovascular Hospitalization Risk Attributable to Cold Temperatures in Hong Kong. Circ. Cardiovasc. Qual. Outcomes 2016, 9, 135-142. [CrossRef] [PubMed]

21. Giang, P.N.; Dung, D.O.; Giang, K.B.; Vinh, H.H.; Rocklov, J. The effect of temperature on cardiovascular disease hospital admissions among elderly people in Thai Nguyen Province, Vietnam. Glob. Health Action 2014, 7, 59-65. [CrossRef] [PubMed]

22. Ponjoan, A.; Blanch, J.; Alves-Cabratosa, L.; Marti-Lluch, R.; Comas-Cufi, M.; Parramon, D.; Del Mar Garcia-Gil, M.; Ramos, R.; Petersen, I. Effects of extreme temperatures on cardiovascular emergency hospitalizations in a Mediterranean region: A self-controlled case series study. Environ. Health 2017, 16, 32. [CrossRef] [PubMed]

23. Plavcova, E.; Kysely, J. Effects of sudden air pressure changes on hospital admissions for cardiovascular diseases in Prague, 1994-2009. Int. J. Biometeorol. 2014, 58, 1327-1337. [CrossRef] [PubMed]

24. Tsangari, H.; Paschalidou, A.K.; Kassomenos, A.P.; Vardoulakis, S.; Heaviside, C.; Georgiou, K.E.; Yamasaki, E.N. Extreme weather and air pollution effects on cardiovascular and respiratory hospital admissions in Cyprus. Sci. Total Environ. 2016, 542, 247-253. [CrossRef]

25. Onozuka, D.; Hagihara, A. Within-summer variation in out-of-hospital cardiac arrest due to extremely long sunshine duration. Int. J. Cardiol. 2017, 231, 120-124. [CrossRef]

26. Fang, X.; Fang, B.; Wang, C.F.; Xia, T.; Bottai, M.; Fang, F.; Cao, Y. Relationship between fine particulate matter, weather condition and daily non-accidental mortality in Shanghai, China: A Bayesian approach. PLoS ONE 2017, 12, e0187933. [CrossRef]

27. Shanghai Bureau of Statistics. Shanghai Statistical Yearbook; China Statistics Press: Beijing, China, 2017.

28. Liu, J.; Han, Y.; Tang, X.; Zhu, J.; Zhu, T. Estimating adult mortality attributable to PM2.5 exposure in China with assimilated PM2.5 concentrations based on a ground monitoring network. Sci. Total Environ. 2016, 568, 1253-1262. [CrossRef]

29. Vanos, J.K.; Cakmak, S.; Bristow, C.; Brion, V.; Tremblay, N.; Martin, S.L.; Sheridan, S.S. Synoptic weather typing applied to air pollution mortality among the elderly in 10 Canadian cities. Environ. Res. 2013, 126, 66-75. [CrossRef]

30. Ravindra, K.; Rattan, P.; Mor, S.; Aggarwal, A.N. Generalized additive models: Building evidence of air pollution, climate change and human health. Environ. Int. 2019, 132, 104987. [CrossRef]

31. Thelen, B.; French, N.H.F.; Koziol, B.W.; Billmire, M.; Owen, R.C.; Johnson, J.; Ginsberg, M.; Loboda, T.; $\mathrm{Wu}$, S.L. Modeling acute respiratory illness during the 2007 San Diego wildland fires using a coupled emissions-transport system and generalized additive modeling. Environ. Health 2013, 12, 94. [CrossRef]

32. Dehghan, A.; Khanjani, N.; Bahrampour, A.; Goudarzi, G.; Yunesian, M. The relation between air pollution and respiratory deaths in Tehran, Iran- using generalized additive models. BMC Pulm. Med. 2018, 18, 49. [CrossRef] [PubMed]

33. Dominici, F.; McDermott, A.; Zeger, S.L.; Samet, J.M. On the use of generalized additive models in time-series studies of air pollution and health. Am. J. Epidemiol. 2002, 156, 193-203. [CrossRef] [PubMed]

34. Gasparrini, A.; Armstrong, B.; Kenward, M.G. Distributed lag non-linear models. Stat. Med. 2010, 29, 2224-2234. [CrossRef] [PubMed]

35. Schwartz, J. Harvesting and long term exposure effects in the relation between air pollution and mortality. Am. J. Epidemiol. 2000, 151, 440-448. [CrossRef]

36. World Health Organization. WHO Air Quality Guidelines for Particulate Matter, Ozone, Nitrogen Dioxide and Sulfur Dioxide: Global Update 2005: Summary of Risk Assessment; World Health Organization: Geneva, Switzerland, 2006.

37. Lu, F.; Xu, D.; Cheng, Y.; Dong, S.; Guo, C.; Jiang, X.; Zheng, X. Systematic review and meta-analysis of the adverse health effects of ambient PM2.5 and PM10 pollution in the Chinese population. Environ. Res. 2015, 136, 196-204. [CrossRef] 
38. Achilleos, S.; Kioumourtzoglou, M.A.; Wu, C.D.; Schwartz, J.D.; Koutrakis, P.; Papatheodorou, S.I. Acute effects of fine particulate matter constituents on mortality: A systematic review and meta-regression analysis. Environ. Int. 2017, 109, 89-100. [CrossRef]

39. Lee, H.; Honda, Y.; Hashizume, M.; Guo, Y.L.; Wu, C.F.; Kan, H.; Jung, K.; Lim, Y.H.; Yi, S.; Kim, H. Short-term exposure to fine and coarse particles and mortality: A multicity time-series study in East Asia. Environ. Pollut. 2015, 207, 43-51. [CrossRef]

40. Guo, Y.S.; Ma, Y.; Ji, J.J.; Liu, N.; Zhou, G.H.; Fang, D.K.; Huang, G.W.; Lan, T.; Peng, C.Q.; Yu, S.Y. The relationship between extreme temperature and emergency incidences: A time series analysis in Shenzhen, China. Environ. Sci. Pollut. Res. 2018, 25, 36239-36255. [CrossRef]

41. Vanos, J.K.; Hebbern, C.; Cakmak, S. Risk assessment for cardiovascular and respiratory mortality due to air pollution and synoptic meteorology in 10 Canadian cities. Environ. Pollut. 2014, 185, 322-332. [CrossRef]

42. Chen, K.; Wolf, K.; Breitner, S.; Gasparrini, A.; Stafoggia, M.; Samoli, E.; Andersen, Z.J.; Bero-Bedada, G.; Bellander, T.; Hennig, F.; et al. Two-way effect modifications of air pollution and air temperature on total natural and cardiovascular mortality in eight European urban areas. Environ. Int. 2018, 116, 186-196. [CrossRef]

43. Kim, J. Particulate Matter Mortality Rates and Their Modification by Spatial Synoptic Classification. Int. J. Environ. Res. Public Health 2019, 16, 1904. [CrossRef] [PubMed]

44. Talbott, E.O.; Rager, J.R.; Benson, S.; Brink, L.A.; Bilonick, R.A.; Wu, C. A case-crossover analysis of the impact of PM2.5 on cardiovascular disease hospitalizations for selected CDC tracking states. Environ. Res. 2014, 134, 455-465. [CrossRef] [PubMed]

45. Amsalu, E.; Wang, T.Q.; Li, H.B.; Liu, Y.; Wang, A.X.; Liu, X.T.; Tao, L.X.; Luo, Y.X.; Zhang, F.; Yang, X.H.; et al. Acute effects of fine particulate matter (PM2.5) on hospital admissions for cardiovascular disease in Beijing, China: A time-series study. Environ. Health 2019, 18, 70. [CrossRef] [PubMed]

46. Seaton, A.; MacNee, W.; Donaldson, K.; Godden, D. Particulate air pollution and acute health effects. Lancet 1995, 345, 176-178. [CrossRef]

47. Franchini, M.; Mannucci, P.M. Air pollution and cardiovascular disease. Thromb. Res. 2012, 129, $230-234$. [CrossRef] [PubMed]

48. Kan, H.D.; Wong, C.M.; Vichit-Vadakan, N.; Qian, Z.M.; Teams, P.P. Short-term association between sulfur dioxide and daily mortality: The Public Health and Air Pollution in Asia (PAPA) study. Environ. Res. 2010, 110, 258-264. [CrossRef]

49. Lin, H.L.; Zhang, Y.H.; Liu, T.; Xiao, J.P.; Xu, Y.J.; Xu, X.J.; Qian, Z.M.; Tong, S.L.; Luo, Y.; Zeng, W.L.; et al. Mortality reduction following the air pollution control measures during the 2010 Asian Games. Atmos. Environ. 2014, 91, 24-31. [CrossRef]

50. Sun, D.; Fang, J.; Sun, J.Q. Health-related benefits of air quality improvement from coal control in China: Evidence from the Jing-Jin-Ji region. Resour. Conserv. Recycl. 2018, 129, 416-423. [CrossRef]

51. Cherrie, J.W.; Apsley, A.; Cowie, H.; Steinle, S.; Mueller, W.; Lin, C.; Horwell, C.J.; Sleeuwenhoek, A.; Loh, M. Effectiveness of face masks used to protect Beijing residents against particulate air pollution. Occup. Environ. Med. 2018, 75, 446-452. [CrossRef]

52. Tong, H. Dietary and pharmacological intervention to mitigate the cardiopulmonary effects of air pollution toxicity. Biochim. Biophys. Acta 2016, 1860, 2891-2898. [CrossRef]

53. Rainham, D.G.; Smoyer-Tomic, K.E.; Sheridan, S.C.; Burnett, R.T. Synoptic weather patterns and modification of the association between air pollution and human mortality. Int. J. Environ. Health Res. 2005, 15, 347-360. [CrossRef] [PubMed]

(C) 2020 by the authors. Licensee MDPI, Basel, Switzerland. This article is an open access article distributed under the terms and conditions of the Creative Commons Attribution (CC BY) license (http://creativecommons.org/licenses/by/4.0/). 